\title{
EFFECTS OF HIGH OR LOW SODIUM INTAKE IN SPONTANEOUSLY HYPERTENSIVE RATS
}

\author{
Kyuzo Aoki, M. D., D. M. Sc., Yukio Yamori, M.D., D. M. Sc., \\ AKira Ooshima, M. D., and Kozo OKamoto, M. D., D. M. Sc.
}

\begin{abstract}
Spontaneously hypertensive rats (SHR) developed and maintained hypertension in spite of low sodium intake. The development of hypertension was accelerated and hypertension was enhanced by chronic excess sodium intake ( $1 \%$ salt in drinking water with or without high sodium diet). Various substrains of SHR showed some difference in sensitivity to salt ingestion. Consequently, hypertension in SHR is mainly determined by genetic factors, the minor part of which interacts with excess salt intake especially in several substrains of SHR.
\end{abstract}

$\mathbf{T}$

HE strain of spontaneously hypertensive rats (hereafter abbreviated as SHR), separated by Okamoto and Aoki, ${ }^{1}$ was started by the mating between a male Wistar rat from the Animal Center Laboratory, Kyoto University (hereafter abbreviated as Wistar-Kyoto or WK) with mild hypertension $(145-175 \mathrm{mmHg})$ and a female with relatively high blood pressure (130$140 \mathrm{mmHg}$ ), and the most severe hypertensive rats in the subsequent litters were selected for sib-mating. One hundred per cent occurrence of hypertension with the subsequent development of hypertensive cardiovascular lesions in the third generation and thereafter showed that SHR had hypertension as a cardiovascular disease and they were studied from various aspects? This strain was finally established as an inbred strain after 20 generations of sib-breeding ${ }^{3}$ and has now reached the $F_{28}$ generation. The establishment of the hypertensive strain itself indicated that the most important factors for the development of hypertension were genetic ones and the detailed

Key Words: Hypertension

Low and High Sodium Diet

Salt Toxicity and Sensitivity

Substrains of Spontaneously Hypertensive Rats mode of the heredity of hypertension was studied in $\mathrm{SHR}^{3-5}$

Hypertension in animals is experimentally produced by many manipulations, such as in renal, renoprival, adrenal regeneration, DCA, neurogenic and salt hypertensions. These hypertensions are equivalent to secondary hypertension in human beings. On the other hand, SHR, in which genetic factors greatly contribute to the development of hypertension, seem to be the best model for the study on human essential hypertension ${ }^{1-3}$ and this was supported by hemodynamic studies of Folkow et al. on SHR! As in essential hypertension, possible interactions between genetic and environmental factors were supposed to be in SHR, although the degree of genetic determination of blood pressure was as high as $80-90 \% ?^{3-5}$ Extreme alterations of environmental factors such as various stress loadings ${ }^{7}$ and high fat-cholesterol-salt diet feedings 8,9 were confirmed to affect the development of hypertension and/or hypertensive cardiovascular complications.

Especially, the relationship between salt and hypertension in $\operatorname{man}^{10-12}$ has attracted much attention. Experimental chronic salt loading pro-

(Received for publication, May 5, 1972)

Department of Pathology, Faculty of Medicine, Kyoto University, Kyoto

(Director: Prof. K. Okamoto)

* Present Address: Department of Medicine, Nagoya City University, School of Medicine, Nagoya

This study was supported by a Grant-in-Aid for Scientific Research from the Japanese

Ministry of Education. 
duced hypertension in animals, ${ }^{13,14}$ and the roles of genetic predisposition and of sodium intake for the development and maintenance of hypertension were investigated in hypertension-prone rats by Dahl et al..$^{15,16}$ and also in SHR.$^{17-20}$ As there seems to be a little discrepancy among the conclusions of the previous reports as to the sensitivity of SHR to salt ingestion, the present studies were undertaken to reevaluate precisely the role of sodium intake and its interaction of genetic factors in the development of hypertension by observing 1) effect of low and high sodium diet on the development of hypertension, and 2) effect "of salt loading on blood pressure in the various" substrains of SHR with different genetic traits $3,8,9,21,22$

\section{Materials and Methods}

Male spontaneously hypertensive rats ( $\mathrm{Oka}$ moto and $A o k i$ ) (SHR) ${ }^{1-3}$ were used with normotensive rats of Wistar-Kyoto, from the ancestors of which SHR had been separated. In the first experiment 16 male SHR $\left(\mathrm{F}_{4}\right)$ were divided into 4 groups which were fed on the following diets from the 5 th week of age: group 1 ; low sodium diet $(0.079 \%)$, group 2 ; standard sodium diet $(0.276 \%)$, groups 3 and 4 ; high sodium diet $(2.76 \%)$. All diets were supplied from the Orien- tal Yeast Co., Tokyo. Groups 1, 2 and 3 were given tap water for drinking and libitum and group 4 was given $1 \%$ salt in drinking water. In the second experiment 17 to 31 male SHR $\left(F_{25,26}\right)$ of $A_{1}, A_{1}-s b, A_{2}, A_{3}, B_{1}, B_{2}, B_{2}-o b$, and $C$ substrains, $3,8,9,21,22$ respectively, were used with 14 male rats of Wistar-Kyoto (WK). SHR from each substrain and WK were divided into two groups at the age of 6 to 8 weeks and one group was loaded with $1 \%$ salt in the drinking water thereafter for 15 weeks, while the other was given tap water. They were fed on standard stock chow diet CA-1 (Japan CLEA Co., Tokyo).

All rats were housed under stable conditions of temperature $\left(22-25^{\circ} \mathrm{C}\right)$ and humidity (50$60 \%$ ). Blood pressure was measured indirectly by the tail-plethysmographic method ${ }^{1}$ once weekly without anesthesia.

\section{RESULTS}

1. Effect of high or low sodium diet on the development of spontaneous hypertension (Fig.1)

Although no difference in blood pressure was noted among groups 1 (low sodium diet), 2 (standard sodium diet), 3 (high sodium diet) and 4 (high sodium diet $+1 \%$ salt in drinking water)

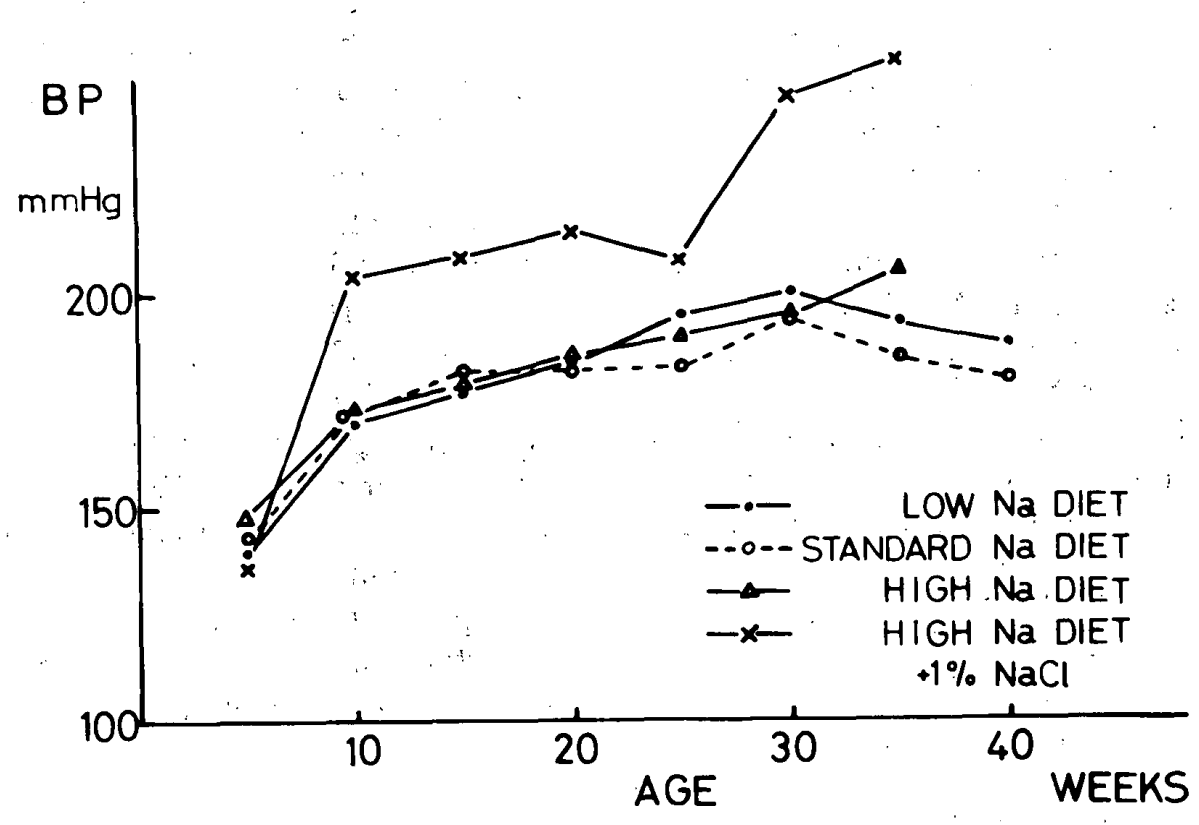

Fig.1. Effects of sodium intake on blood pressure in male spontaneously hypertensive rats fed on diet containing low sodium $(0.079 \%)$, standard sodium $(0.276 \%)$ and high sodium $(2.76 \%)$ with or without $1 \%$ salt in drinking water. 
at the beginning of this experiment, group 4 developed hypertension earlier than the others as shown in Fig.1. At the 5th week of experiment (10 weeks after birth), blood pressure in group 4 $(204 \pm 8 \mathrm{mmHg}, \mathrm{M} \pm \mathrm{SD}$ ) was significantly ( $\mathrm{p}<$ $0.01)$ higher than those in groups $1(170 \pm 13)$, $2(172 \pm 16)$ and $3(173 \pm 11)$. During 30 weeks of experiment there was no significant difference in blood pressure in groups 1,2 and 3. SHR developed hypertension without any excess salt intake (group 2) and even under dietary condition of low sodium (group 1). Neither effective acceleration of the development of hypertension nor augmentation of its grade was observed in group 3 fed on high sodium diet $(2.76 \%)$. Sodium effect on hypertension was more marked when the drinking water was additively loaded with $1 \%$ salt than when diet only was loaded but not the drinking water.

Growth was slightly slowed down in the low and high sodium diet groups compared with that in the standard diet group 2. Their body weights in gram at the 5th (and 20th) weeks of experiment were as follows $(\mathrm{M} \pm \mathrm{SD})$ : group $1 ; 215 \pm$ 7 (316 \pm 16$)$, group 2; $303 \pm 20(363 \pm 10)$, group $3 ; 263 \pm 10(305 \pm 10)$ and group $4 ; 214 \pm$ $35(267 \pm 32)$.

All rats were alive at the 15 th week of experi-

TABLE I BLOOD PRESSURE IN MALE SPONTANEOUSLY HYPERTENSIVE RATS (SHR) AND MALE WISTAR-KYOTO RATS (WK) LOADED WITH OR WITHOUT 1\% SALT IN DRINKING WATER

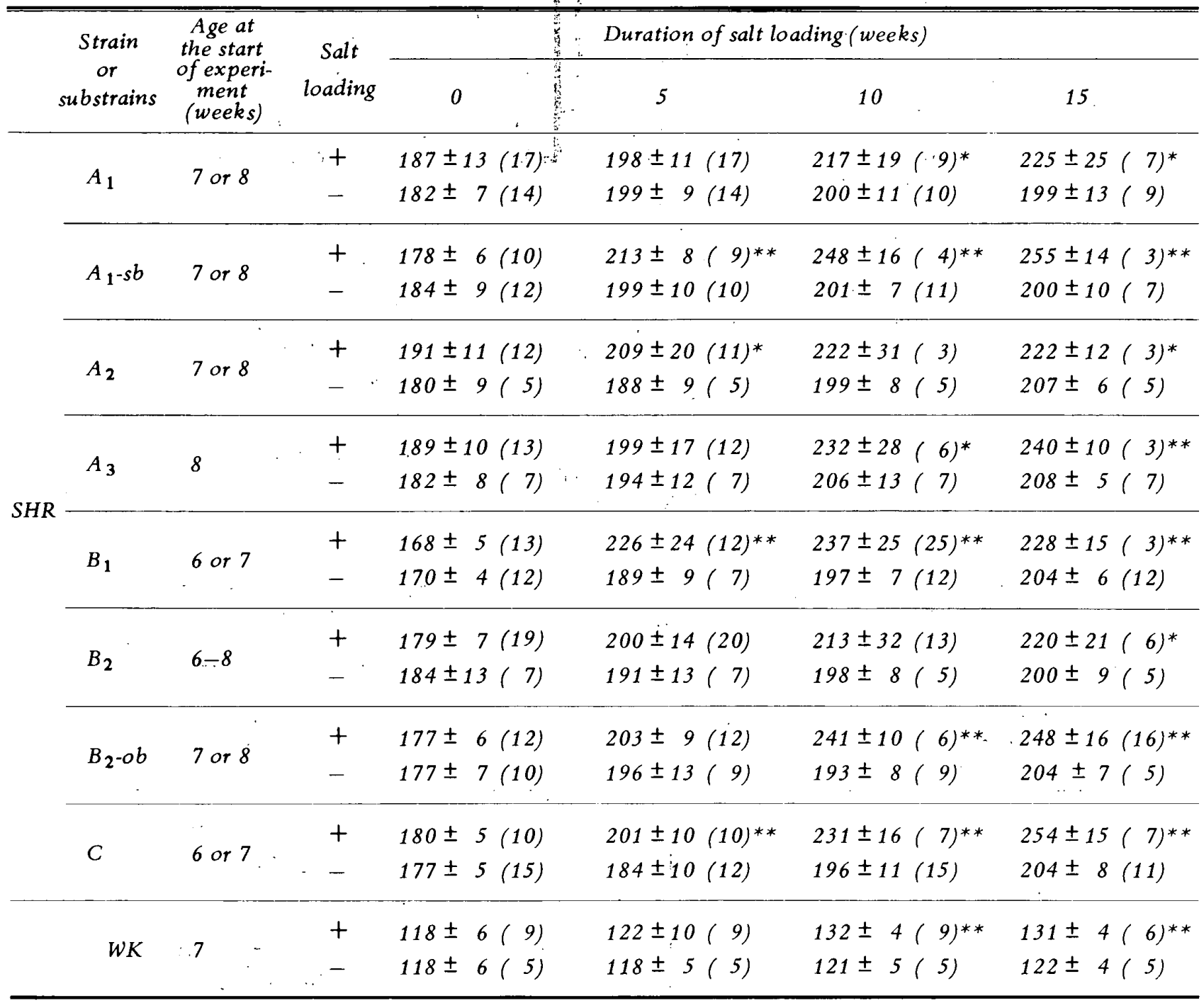

$M \pm S D$

( ): Number of rats checked for blood pressure.

**, *: Statistically significant differences $(P<0.01,0.01<P<0.05$, respectively) from the non-salt-loaded group in the same substrain. 

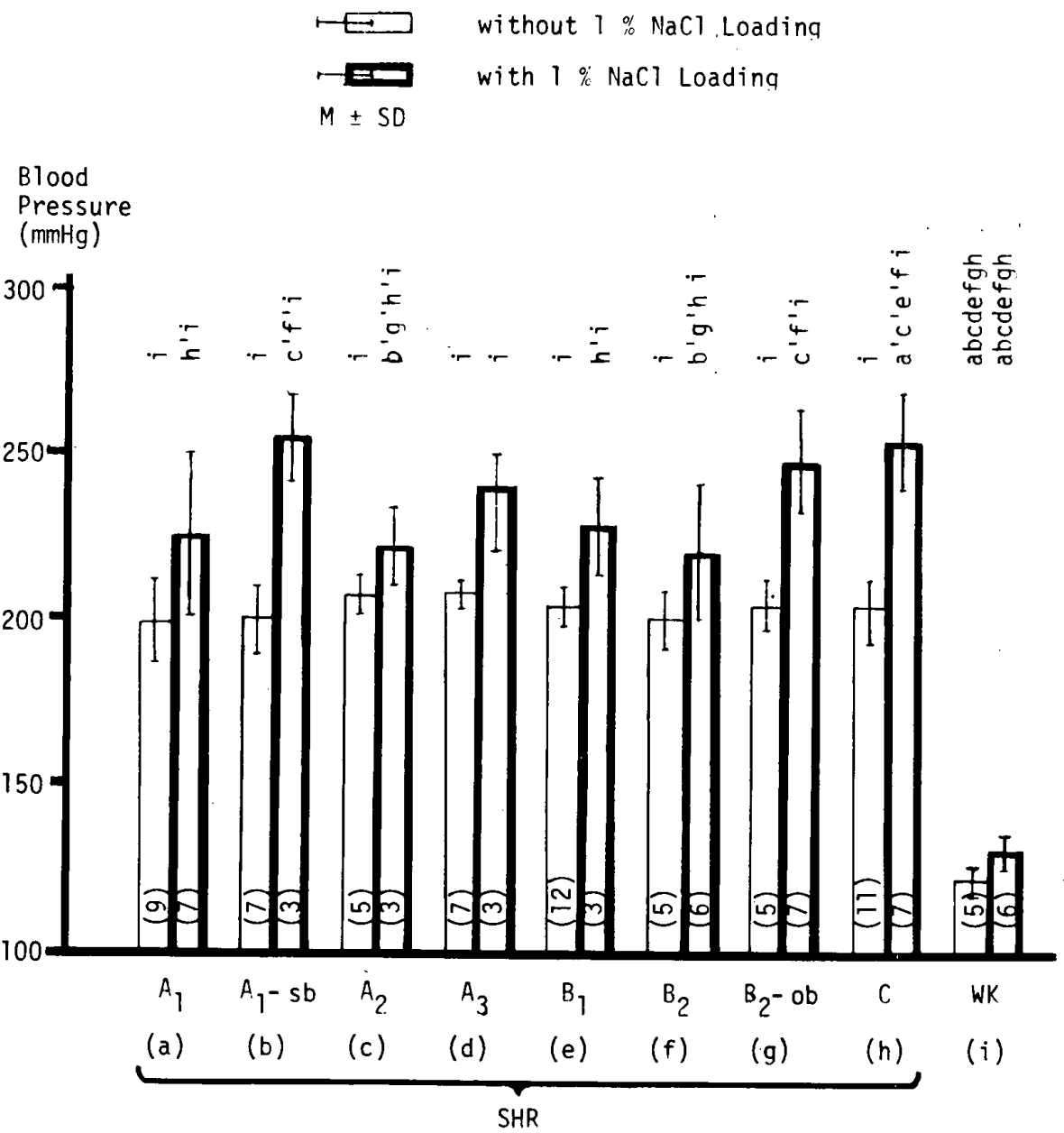

Fig.2. Blood pressure in male spontaneously hypertensive rats (SHR) and male normotensive Wistar-Kyoto rats (WK) loaded with or without $1 \%$ salt in drinking water for 15 weeks.

( ): Number of rats checked for blood pressure.

Statistical differences: a $\left(a^{\prime}\right), b\left(b^{\prime}\right), c\left(c^{\prime}\right), d\left(d^{\prime}\right), e\left(e^{\prime}\right), f\left(f^{\prime}\right)$, $\mathrm{g}\left(\mathrm{g}^{\prime}\right), \mathrm{h}\left(\mathrm{h}^{\prime}\right)$ and $\mathrm{i}\left(\mathrm{i}^{\prime}\right)$ show statistically significant differences, $\mathrm{p}<0.01(\mathrm{p}<0.05)$, from the values of $\mathrm{A}_{1}, \mathrm{~A}_{1}-\mathrm{sb}, \mathrm{A}_{2}, \mathrm{~A}_{3}, \mathrm{~B}_{1}$, $B_{2}, B_{2}-o b, C$ and $W K$, respectively.

TABLE II RELATIONSHIP BETWEEN SALT SENSITIVITY AND TOXICITY IN VARIOUS SUBSTRAINS IN SPONTANEOUSLY HYPERTENSIVE RATS

\begin{tabular}{|c|c|c|}
\hline $\begin{array}{ll}\begin{array}{l}\text { Salt } \\
\text { toxicity } \\
\text { [Mortality rate] }\end{array} & \begin{array}{l}\text { Salt sensitivity } \\
\text { (Blood pressure) }\end{array}\end{array}$ & $\begin{array}{c}\text { High } \\
(248-255)\end{array}$ & $\begin{array}{c}\text { Low } \\
(220-228)\end{array}$ \\
\hline \multirow[t]{2}{*}{ High [62-83] } & $A_{1-s b}[70]$ (255) & $\begin{array}{l}A_{2}[83](222) \\
B_{1}[62](228)\end{array}$ \\
\hline & \multicolumn{2}{|c|}{$A_{3}[43](240)$} \\
\hline Low $[0-33]$ & $\begin{array}{l}C[0](254) \\
B_{2}-o b[20](248)\end{array}$ & $\begin{array}{l}A_{1}[17](225) \\
B_{2}[33](220)\end{array}$ \\
\hline
\end{tabular}

( ): Blood pressure in $\mathrm{mmHg}$ after 15 weeks of $1 \%$ salt loading in drinking water.

[ ]: Mortality rate in \% during 15 weeks of the salt loading. 
ment. However, the life span was shortened in the groups fed on low or high salt regimen and final mortality rates at the 45th week of experiment were as follows: group $1(50 \%), 2(25 \%)$, 3 and $4(100 \%)$.

2. Effect of high salt intake on blood pressure in various substrains of SHR (Table I, II and Fig.1)

SHR $\left(\mathrm{F}_{25,26}\right)$ at present are classified into the following 8 substrains; $A_{1}, A_{1}$-sb, $A_{2}, A_{3}, B_{1}$, $\mathrm{B}_{2}, \mathrm{~B}_{2}-\mathrm{ob}$ and $\mathrm{C}$, according not only to genealogy, but also to isozyme analyses, responses to hypercholesterolemic diet, susceptibility to hypertensive cardiovascular lesions and others? $3,8,9,21,22$ Non-salt-loaded groups of each substrain developed almost a similar grade of hypertension. Although there were some statistically significant differences in blood pressure among these substrains at 0,5 th and 10 th week of experiment, no significant difference was observed at the 15 th week of experiment (2123 weeks after birth) when gene actions were supposed to be fully developed in SHR4

One per cent salt loading in drinking water accelerated the development of hypertension and enhanced hypertension in all substrains of SHR and also in normotensive rats of Wistar-Kyoto as shown in Table I. Salt-loaded groups of $A_{1}-s b$, $A_{2}, B_{1}$ and $C$ showed significantly higher blood pressure than the non-salt-loaded group of each substrain even at the 5 th week of experiment. In all salt-loaded groups including WK, increases in blood pressure were significantly greater than those in non-salt-loaded control groups at the 15 th week of experiment. As blood pressures in non-salt-loaded groups were not different among substrains at this time, blood pressures in saltloaded groups were compared with each other among substrains (Fig.2). The groups with average blood pressure over $240 \mathrm{mmHg}$ were $A_{1}$-sb ( $255 \mathrm{mmHg}), \mathrm{C}(254 \mathrm{mmHg}), \mathrm{B}_{2}$-ob $(248 \mathrm{mmHg})$ and $\mathrm{A}_{3}(240 \mathrm{mmHg})$, while those with average blood pressure below $230 \mathrm{mmHg}$ were $B_{1}(228$ $\mathrm{mmHg}), \mathrm{A}_{1}(225 \mathrm{mmHg}), \mathrm{A}_{2}(222 \mathrm{mmHg})$ and $B_{2}(220 \mathrm{mmHg})$. As some of the former groups, $A_{1}$-sb, $C$ and $B_{2}-o b$ showed a significant difference in blood pressure from some of the latter groups, $A_{2}$ and $B_{2}$, the former substrains were considered to be rather more sensitive to salt loading than the latter substrains.

As for salt toxicity many rats died of cardiovascular lesions 5-10 weeks after the start of salt loading. Mortality rates were calculated at the 15 th week of experiment and is shown in Table II in relation to the above-mentioned, relative salt sensitivity. All cases were checked by autopsy and the detailed findings of histopathological examination on hypertensive cardiovascular lesions are to be reported elsewhere. Although a parallelism between salt toxicity and sensitivity was noted in $A_{1}$-sb with high toxicity and sensitivity, $\mathbf{A}_{3}$ with intermediate toxicity and sensitivity and also in $A_{1}$ and $B_{2}$ with low toxicity and sensitivity, there seemed to be a discrepancy, too, between salt sensitivity and toxicity in $C$ and $B_{2}$-ob with high sensitivity and low toxicity as well as in $A_{2}$ and $B_{1}$ with low sensitivity and high toxicity.

\section{Discussion}

Although no definite conclusion has been obtained yet on the role of salt in the pathogenesis of essential hypertension in human beings, genetic factors are evidently important in essential hypertension ${ }^{23,24}$ and also in spontaneous hypertension in animals!-5,25-28 In SHR, hypertension is inherited additively and mainly determined by a relatively small number of major genes. ${ }^{3-5}$ The present study showed that hypertension developed without the aid of excess salt ingestion and even under sodium restriction, supported the previous reports ${ }^{17,19,20}$ and confirmed the importance of genetic factors in hypertension of SHR. In this point SHR is different from Dahl's sensitive strain in which an interaction between genes and environmental factors (chronic salt ingestion) is indispensable for the development of hypertension! $!^{15,16}$

In regard to the sensitivity to chronic salt ingestion in SHR, there has been a little difference in the conclusions of the previous reports on SHR whether they are sensitive ${ }^{18,19}$ or rather insensitive. ${ }^{17}$ This debate seems mainly to come from the difference in experimental regimens of sodium loading. The present experiment showed that high sodium diet $(2.76 \%)$ plus plain water for drinking was ineffective, while the same high sodium diet plus $1 \%$ salt in drinking water or only the latter was evidently effective for the augmentation of hypertension. The previous experiment using high salt diet without salt in drinking water ${ }^{17}$ resulted in the insensitivity to salt ingestion and the experiments using $1 \%$ salt in drinking water ${ }^{18,19}$ confirmed the sensitivity in SHR. One per cent salt in drinking water is more effective than $1 \%$ sodium diet plus plain water. It may be simply because sodium in diet 
is diluted for excretion with an increased amount of water taken together, for exaggerated natruresis follows sodium loading both in hypertensive men $^{29}$ and in SHR ${ }^{30}$

The augmentation of hypertension by chronic sodium ingestion was observed in SHR and an interaction between hypertensinogenic genes and loaded sodium was presumed to exist also in SHR. As sensitivity to excess salt intake was different among various substrains of SHR, genetic factors involved in sodium metabolism might be somewhat different among these substrains. These substrains have some difference in susceptibility to hypertensive vascular lesions; for example, $A_{1}$-sb and $A_{3}$ are vulnerable while $B_{2}$ including $\mathrm{B}_{2}$-ob is rather resistant to the lesions ${ }^{3}$, $8,9,21,22$, although their blood pressure levels are similar to each other. Chronic salt ingestion is toxic, for it induces cardiovascular lesions, especially in hypertension. 32 Salt toxicity and sensitivity were observed in this experiment as mortality rate and enhancement of hypertension, respectively. These substrains can be tentatively classified into 4. groups, with high sensitivity and toxicity, with low sensitivity and toxicity, with high sensitivity and low toxicity, and with low sensitivity and high toxicity. It is noteworthy that there is a discrepancy between salt sensitivity and toxicity in some substrains such as $A_{2}$ and $B_{1}$ with high toxicity and low sensitivity, as well as $C$ and $B_{2}$ oob with high sensitivity and low toxicity. The former might have expired before they showed enhanced hypertension because of salt toxicity. However, the latter substrains seemed to be resistant to salt-induced vascular lesions in spite of the augmentation of hypertension. Therefore, genetic disposition about salt toxicity and sensitivity might be independent from each other, Further separation of the substrains with these extreme characteristics, and the detailed analysis of substrain-difference in salt toxicity and sensitivity are expected to contribute to the clarification of an interaction between genetic disposition and excess salt intake for the induction of hypertensive vascular diseases such as cerebral hemorrhage and softening.

\section{SUMMARY}

Effects of sodium restriction or chronic sodium excess on blood pressure were observed in male spontaneously hypertensive rats (Okamoto and Aoki) (SHR) and various substrains of SHR in order to clarify the role of sodium and its interaction with genetic factors in spontaneous hyperten- sion, and the following results were obtained.

1) Hypertension developed in SHR fed on low sodium diet $(0.079 \%)$ and the grade of hypertension in these rats was not greatly different from that in SHR fed on standard or high sodium diet ( 0.276 or $2.76 \%$, respectively) with tap water for drinking.

2) Development of hypertension was accelerated and its grade was augmented in SHR fed on high sodium diet $(2.76 \%)$ with $1 \%$ salt in drinking water.

3) Hypertension in various substrains of SHR was enhanced by $1 \%$ salt loading in drinking water for 5 to 15 weeks.

4) Some substrains of SHR were more sensitive to the same salt regimen than the others, and a discrepancy between salt sensitivity and toxicity was observed in some substrains of SHR.

5) These results indicated that hypertension in SHR was genetically determined to the major extent and that alterations of salt intake interacted with genetic predisposition to modify the grade of hypertension or the course of hypertensive vascular diseases.

\section{REFERENCES}

1. OKAMOTO, K. \& AOKI, K.: Development of a strain of spontaneously hypertensive rats. Jap. Circul. J. 27: 282, 1963.

2. OKAMOTO, K.: Spontaneous hypertension in rats. Int'l Rev. Exp. Pathol., vol.7 (G. W. Richter and M. A. Epstein, eds.), p.227, Academic Press, New York and London, 1969.

3. OKAMOTO, K., YAMORI, Y., OOSHIMA, A., PARK, C., HAEBARA, H., MATSUMOTO, M., TANAKA, T., OKUDA, T., HAZAMA, F., \& KYOGOKU, M.: Establishment of the inbred strain of the spontaneously hypertensive rat and genetic factors involved in hypertension. In "Spontaneous Hypertension" (K. Okamoto, ed.), p.1, Igaku Shoin, Tokyo, 1972.

4. TANASE, H., SUZUKI, Y., OOSHIMA, A., YAMORI, Y., \& OKAMOTO, K.: Genetic analysis of blood pressure in spontaneously hypertensive rats.Jap. Circul. J. 34: 1197, 1970.

5. TANASE, H., SUZUKI, Y, OOSHIMA, A., YAMOQRI, Y., \& OKAMOTO, K.: Further genetic analysis of blood pressure in spontaneously hypertensive rats. In "Spontaneous Hypertension" (K. Okamoto; ed.);p.9, Igaku Shoin, Tokyo, 1972.

6. FOLKOW, B., HALLBÄCK, M., LUNDGREN, Y., SIVERTSSON, R., \& WEISS, L.: The importance of adaptive changes in vascular design for the establishment and maintenance of primary hypertension in man and in spontaneously hypertensive rats. In "Spontaneous Hypertension"' (K. Okamoto, ed.), p.103, Igaku Shoin, Tokyo, 1972.

7. YAMORI, Y., MATSUMOTO, M., YAMABE, H., \& OKAMOTO, K.: Augmentation of spontaneous hypertension by chronic stress in rats. Jap. Circul. 
J. 33: 399, 1969.

8. OKAMOTO, K., 'HAZAMA; F., HAEBARA, H., AMANO, S., TANAKA, T., \& OOSHIMA, A.: Pathology of dietary induced cerebrovascular diseases in spontaneously hypertensive rats. In "Spontaneous Hypertension" (K. Okamoto, ed.), p.129, Igaku Shoin, Tokyo, 1972.

9. HAZAMA, F., TANAKA, T., OOSHIMA, A., HAEBARA, H., AMANO, S., YAMAZAKI, Y., \& OKAMOTO, K.: Dietary effect on cardiovascular lesions in spontaneously hypertensive rats. In "Spontaneous Hypertension" (K. Okamoto, ed.), p.134, Igaku Shoin, Tokyo, 1972.

10. DAHL, L. K.: Possible role of chronic excess salt consumption in the pathogenesis of essential hypertension. Am. J. Cardiol. 8: 571, 1961.

11. GROSS, G., WELlER, J. M., HOOBLER, S. W.: Relationship of sodium and potassium intake to blood pressure. Am. J. Clin. Nutr. 24: 605, 1971.

12. SWAYE, P. S., GIFFORD, R. W., \& BERRETTONI, J. N.: Dietary salt and essential hypertension. Am. J. Cardiol. 29: 32, 1972.

13. SAPIRSTEIN, L. A., BRANDT, W. L., \& DRURY, D. R.: Production of hypertension in the rat by substituting hypertonic sodium chloride solution for drinking water. Proc. Soc. Exper. Biol. Med. 73: 82, 1950 .

14. KOLETSKY, S.: Hypertensive vascular disease produced by salt. Lab. Invest. 7: 377, 1958.

15. DAHL, L. K., HEINE, M., \& TASSINARI, L.: Role of genetic factors in susceptibility to experimental hypertension due to chronic excess salt ingestion. Nature 194: 480, 1962.

16. DAHL, L. K.: HEINE, M., \& TASSINARI, L.: Effects of chronic excess salt ingestion. Further demonstration that genetic factors influence the development of hypertension: Evidence from experimental hypertension due to cortisone and to adrenal regeneration. J. Exper. Med. 122: 533, 1965.

17. LOUIS, W. J., TABEI, R., SPECTOR, S., \& SJOERDSMA, A.: Studies on the spontaneously hypertensive rat. Genealogy, effects of varying salt intake and kinetics of catecholamine metabolism. Circul. Res. 24 and 25: Suppl. I-93, 1969.

18. BARSANTI, J. A., PIllSBURY, H. R. C. III., \& FREIS, E. D.: Enhanced salt toxicity in the spontaneously hypertensive rat. Proc. Soc. Exper. Biol. Med. 136: 565, 1971.

19. TAKATSU, T.: Hypertension and electrolytes. Proc. 17th Gen. Assem. Jap. Med. Assoc., IV, 479, 1967 (in Japanese):

20. LOUIS, W. J., TABEI, R., \& SPECTOR, S.: Effect of sodium intake on inherited hypertension in the rat. Lancet 1283,1971 .

21. OKAMOTO, K., YAMORI, Y., OOSHIMA, A., \& TANAKA, $T$.: Development of substrains in spontaneously hypertensive rats: Genealogy, isozymes and effect of hypercholesterolemic diet. Jap. Circul. J. 36: 461, 1972.

22. YAMORI, Y., OOSHIMA, A., TANAKA, T., HAZAMA, F., \& OKAMOTO, K.: Characteristics of substrains in spontaneously hypertensive rats, especially on different susceptibilities to vascular lesions. Tr. Soc. Pathol. Jap. 61: 1972 (in press).

23. PICKERING, G. W.: Inheritance of high blood pressures. In "Essential Hypertension", p.30, Springer-Verlag, Berlin, 1960.

24. PLATT, R.: The nature of essential hypertension. In “Essential Hypertension", p.39, Springer-Verlag, Berlin, 1960.

25. ALEXANDER, N., HINSHAW, L. B., \& DRURY, D. R.: Development of a strain of spontaneously hypertensive rabbits. Proc. Soc. Exper. Biol. Med. 86: $855,1954$.

26. SMIRK, F. H. \& HALL, W. H.: Inherited hypertension in rats. Nature 182: 727, 1958.

27. SMIRK, F. H.: Characteristics of the New Zealand strain of genetically hypertensive rats considered in relation to essential hypertension. In "Spontaneous Hypertension" (K. Okamoto, ed.), p.250, Igaku Shoin, Tokyo, 1972.

28. PHELAN, E. L., CLARK, D. W. J., GRESSON, C. R., \& JONES, D. R.: The development and inheritance of the high blood pressure in the New Zealand strain of rats with genetic hypertension. In "Spontaneous Hypertension" (K. Okamoto, ed.), p.18, Igaku Shoin, Tokyo, 1972.

29. BUCKALEW, V. M. Jr., PUSCHETT, J. B., KINTZEL, J. E., \& GOLDBERG, M.: Mechanism of exaggerated natruresis in hypertensive man: Impaired sodium transport in the loop of Henle. J. Clin. Invest. 48: 1007, 1969.

30: INATOME, T., FURUTA, Y., YOSHIDA, S., KAWAI, Y., KAWAMORI, K., YORIFUJI, S., \& TOMOMATSU, T.: Sodium metabolism and effect of thiazide on sodium depletion in hypertension. Jap. Circul. J. 36: Suppl. 111, 1972 (in Japanese).

31. MENEELY, G. R.\& BALL, C. O. T.: Experimental epidemiology of chronic sodium chloride toxicity and the protective effect of potassium chloride. A.m. J. Med. 31: 713, 1958.

32. HALL, C. H. \& HALL, O.: Augmented salt ingestion and its effect upon salt hypertension and adrenal-regeneration hypertension. Lab. Invest. 13: $1471,1964$. 